\title{
PIONEROS EN CIRUGÍA DE LA MANO DE LA IFSSH
}

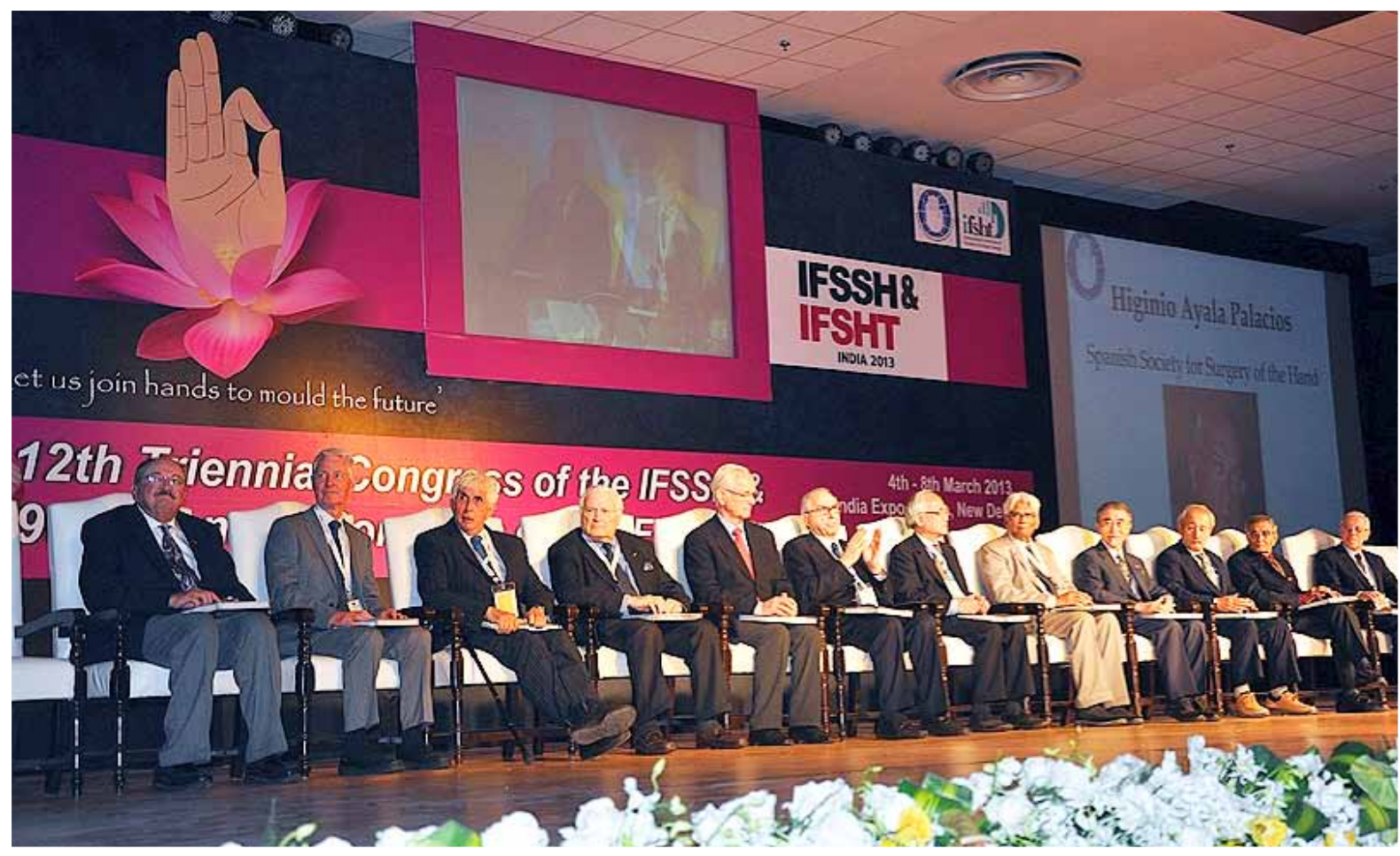

Pioneros en Cirugía de la Mano. Al fondo la imagen del Doctor Higinio Ayala.

Tradicionalmente, durante el congreso de la Federación Internacional de las sociedades para la Cirugía de La Mano (IFSSH), un número de "Pioneros en Cirugía de la Mano" son públicamente reconocidos. Este emblemático reconocimiento se lleva desarrollando desde el tercer congreso de la IFSSH celebrado en Tokio en 1986.

Desde entonces, 123 profesionales cirujanos de mano han sido designados con el prestigioso título de "Pionero en Cirugía de La Mano". A este número debemos añadir este año 19 nuevos pioneros .

Cada tres años, las Sociedades miembros de la IFSSH nominan a los candidatos a esta distinción como "Pioneros", siendo las candidaturas enviadas al Comité evaluador de la IFSSH. Durante la ceremonia de inauguración del congreso de la IFSSH, las nominaciones aceptadas por el Comité evaluador son homenajeadas. Para ser considerado como "Pionero en Cirugía de la Mano", los candidatos deben ser reconocidos por haber contribuido al desarrollo de la Cirugía de La Mano en su país o bien a nivel internacional.

La contribución de los "Pioneros en Cirugía de La Mano" va a influir en las generaciones venideras. Los miembros de la IFSSH expresan su sincero agradecimiento y gratitud a nuestros "Pioneros" por enriquecer nuestra pasión por la Cirugía de la Mano. En este congreso de las IFSSH han sido reconocidos los siguientes cirujanos de mano, destacandoque de la SECMA han sido reconocidos dos cirujanos, como "Pioneros": 


\section{Robert Bechernbaugh}

ASSH

Alan Freeland

AASH

Hildegunde Piza-Katzer

Austrian Society for Surgery of the Hand

Arlindo Pardini

Brazilian Society for Surgery of the Hand

David Evans

British Society for Surgery of the Hand

\section{Graham Lister}

British Society for Surgery of the Hand

Yves Allieu

French Society for Surgery of the Hand

Philippe Shaffar

French Society for Surgery of the Hand

\section{Ulrich Lanz}

German Society for Surgery of the Hand

Panayotis Soucacos

Hellenic Society for Surgery of the Hand

\section{Ping Chung Leung}

Hong Kong Society for Surgery of the Hand

\section{Dinkar Palande}

Indian Society for Surgery of the Hand

Muneaki Abe

Japanese Society for Surgery of the Hand

Ryogo Nakamura

Japanese Society for Surgery of the Hand

Pesi B Chacha

Singapore Society for Surgery of the Hand

\section{Robert WH Pho}

Singapore Society for Surgery of the Hand

José Manuel Antuña Zapico

Spanish Society for Surgery of the Hand

Higinio Ayala Palacios

Spanish Society for Surgery of the Hand

\section{Ayan Gulgoen}

Turkish Society for Surgery of the Hand 


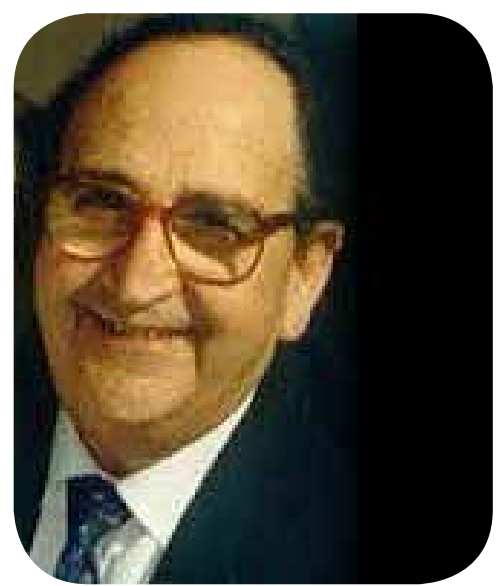

JOSE MANUEL ANTUÑA ZAPICO (1930-)

N o está bien, quizás, que el hijo hable públicamente del padre. Sobre todo cuando está vivo y las vidas de ambos no sólo se engarzan en lo personal, sino también en lo profesional. Muchas veces, sin embargo, he hablado yo del mío, en lo privado.

He transmitido a la gente con la que colaboro y tengo la responsabilidad de formar, muchas ideas y consejos recibidos de él. He contado a menudo cómo, desde muy pequeños, mis hermanos y yo hemos visto a nuestro padre como ejemplo de entrega total, sincera, absoluta y sin reserva a sus enfermos.

Los cinco hemos oído, como ahora oyen sus nietos, que "si no puedes decir algo bueno de alguien, mejor es no decir nada". Nunca, y es literal esta palabra, ha hecho un comentario peyorativo de algo o alguien, y así sigue siendo hoy. En los malos tiempos, que los ha habido, siempre se ha escuchado en mi casa la misma frase sencilla y a la vez llena de confianza en el sentido de nuestras vidas: "seguro que todo esto es para bien, algo bueno nos traerá".

No extraña, por tanto, que allá donde voy por motivos profesionales y coincido con alguno de sus coetáneos o quien le ha conocido, siempre me siento orgulloso de oír lo que sobre él piensan. No hay mayor satisfacción para un hijo que saber que los que han conocido al padre, en el cara a cara, confirman lo que uno ha visto a lo largo de los 45 años que a su lado ha vivido, día a día. Eso es, probablemente, la integridad.
No es pretencioso decir que Antuña Zapico es uno de los pocos cirujanos españoles de su generación cuyo nombre y contribución a la ciencia ha traspasado las fronteras de nuestro país y varios océanos. Cuando yo era pequeño esto no lo veía como extraordinario. Ahora que sé el esfuerzo tan enorme que supone el simple intento de contribuir mínimamente al avance de la ciencia, me admiro de su trabajo.

Desde un pequeñito pueblo asturiano, en la década de los 60 y después de decenas de largos viajes en tren desde casa a Valladolid para finalizar su tesis doctoral, "engendró" a su sexto hijo vivo. Hoy todo el mundo científico vinculado a la cirugía de la mano, desde Oceanía a Europa, conoce esa investigación y relacionan Antuña Zapico con la forma y vascularización del semilunar. En alguna ocasión, en el extranjero, se me han acercado al ver mi apellido a preguntarme si era descendiente de este padre mío; una vez me solicitaron hacerme una foto para poder decir que habían conocido a su hijo. Se entiende, claro, que uno decidiera no seguir su estela como cirujano de mano; inalcanzable.

En su madurez profesional supo combinar su capacidad innovadora científica con la creación, junto a algunos amigos y compañeros, de un gran hospital desde el que se pudiera realizar una labor integral en el cuidado de los enfermos, teniendo a estos como eje central de la actividad médica. Hoy el Centro Médico de Asturias es un referente para la medicina privada en el Principado y el norte de España. Allí acude Antuña Zapico todos los días a trabajar, y el semblante sereno y sus palabras de aliento continúan ayudando a un buen número de enfermos ingresados en el "Centro" por múltiples motivos.

Ha sido un pionero, no hay duda. Lo ha sido en su profesión como cirujano, ayudando a muchos enfermos de primera mano y a otros muchos a través de sus investigaciones. Ha sido pionero al formar una familia que desde él ha procurado inculcar a las siguientes generaciones valores sólidos de entrega a los demás. Ha sido pionero, finalmente, por haber sabido enamorar a una mujer absolutamente increíble, junto a la que está disfrutando una vida plena, sencilla, entregada y alegre.

Samuel Antuña Antuña 


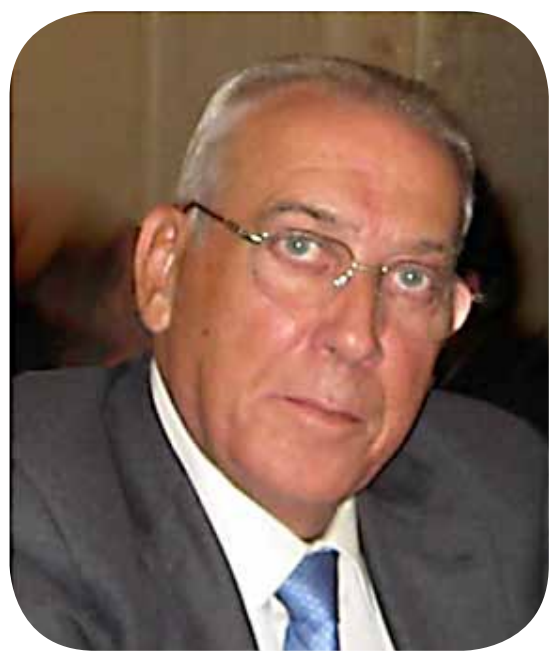

HIGINIO AYALA PALACIOS (1943-2009)

$H$ ace ya casi 5 años que nos dejó mi padre y su recuerdo aún permanece. Nos dejó un excelente cirujano que al final de su carrera se le ha reconocido su valía a nivel mundial como "Pionero" de Cirugía de la Mano. Parece que fue ayer cuando me contaba el último caso al que se había enfrentado y de cómo después de mucho deliberar había llegado a su resolución. Últimamente discutíamos nuestros casos juntos, cada uno con su punto de vista diferente, pero con el orgullo de ver cómo su hijo seguía sus pasos. He tenido la gran suerte de haber aprendido la profesión de grandes maestros de la cirugía de mano y la microcirugía, pero entre todos ellos mi padre fue el primero.

Higinio Ayala Palacios nació el 10 de enero de 1943 y fue el menor de tres hermanos. Vivió la medicina desde pequeño influenciado por su padre quien fue médico también. Contrajo matrimonio con mi madre, María Dolores, en 1968 y tuvieron cuatro niños. Todavía me acuerdo de aquellas tardes en las que traía su proyector de diapositivas a la mesa de la cocina y preparaba las charlas con sus hijos como espectadores, mientras nos comíamos el bocata de chorizo de la merienda. Fue entonces cuando observé con ojos de niño el milagro de ver cómo mi padre era capaz de recuperar la función de las manos destrozadas, de los brazos paralíticos,... y yo le preguntaba con inocencia: "Eso lo has hecho tú?", y él me respondía: "Esto es lo que hago cuando voy a trabajar todos los días". Quizás, esos mo- mentos en los que como niño no llegaba del todo a comprender, fueron los que pusieron la semilla del cirujano que soy hoy.

Después de completar su licenciatura en Medicina y Cirugía por la Universidad de Navarra en 1968, pasó a ser miembro del Departamento de Cirugía Ortopédica y Traumatología de la Clínica Universitaria de Navarra (CUN) como residente, hasta que finalizó su entrenamiento en 1973. Destacó en el estudio de los nervios periféricos, campo en el que obtuvo cum laude en su tesis doctoral, recibiendo el premio extraordinario de la SECOT por sus investigaciones en este campo. En 1973 conoció al profesor Hanno Millesi, en Viena, donde realizó una formación post doctoral de 6 meses y en donde adquirió un extenso conocimiento de uno de los pioneros en la cirugía de los nervios periféricos.

Permaneció en el mismo departamento de la CUN colaborando con su jefe, el Dr Cañadel, como consultor, hasta 1983. Durante este tiempo desempeñó importantes labores tanto asistenciales como docentes llegando a ser Profesor Asociado de la facultad de medicina y director de importantes tesis doctorales. Fue pionero en desarrollar los primeros cursos teórico-prácticos de Microcirugía en España.

Posteriormente, pasó a formar parte del Departamento de Ortopedia y Traumatología del Hospital de Navarra como jefe de la Unidad de Cirugía de miembro superior y posteriormente como Jefe de Servicio hasta el 200 I. En ese periodo, como estudiante de medicina, tuve la oportunidad de hacer las prácticas junto a él. Eran mis primeras prácticas quirúrgicas y no se me olvidará la mirada de reojo de mi padre cuando pisé el quirófano por primera vez y observé la primera cirugía. Mi cara de asombro y admiración se mezclaron entre la multitud de preguntas que le hice durante toda la mañana acerca de los casos de ese día y él las respondía con similar entusiasmo. Creo que pensó: "Bien, ... tiene alma de cirujano", porque se le veía una sonrisa enorme de oreja a oreja cuando llegamos a casa y mi madre nos preguntó cómo nos había ido el día.

Pero fue siendo residente de Cirugía Plástica y Reparadora cuando en realidad pude darme cuenta de la importancia de los casos a los que se enfrentaba y todo el trabajo científico que había detrás de cada caso resuelto. Aproveché las tardes libres que me quedaban entre los días de guardia del hospital para ayudarle en su práctica privada y aprender de uno de los mejores cirujanos de mano con los que me he encontrado a lo 
largo de mi carrera.Y era mi padre. Entonces era joven e inexperto y no llegué a reconocer su valía en toda su amplitud por el simple hecho de tenerlo tan cerca.

Es de destacar, la mención especial realizada por el Dr Szabo sobre la figura de mi padre en la sesión de los "Pioneros en Cirugía de La Mano" en la que transmitió públicamente sus condolencias a mi familia, así como a toda la Sociedad Española de Cirugía de las Mano por la pérdida de tan importante figura.

Era un cirujano brillante y un pionero de su época. Por todos estos momentos tan intensos, muchas gracias Papá.Te echamos de menos.

Higinio Ayala Gutierrez 